\title{
HIV and AIDS: looking ahead
}

\author{
Robin A Weiss
}

\begin{abstract}
Although the future of HIV science is uncertain, we need to reappraise HIV diversity, pathogenesis and immunity. The AIDS pandemic threatens the success of existing vaccine programs and may accelerate the emergence of new infectious diseases.
\end{abstract}

\begin{abstract}
$A^{\mathrm{p}}$ pollo conferred on Cassandra the gift of clairvoyance but later added the caveat that no-one would listen to her prophesy; thus, her warnings of the fall of Troy and the House of Agamemnon went unheeded. Doctors and scientists are less farsighted, and making predictions exposes us to ridicule in hindsight. Not long after the US Surgeon General declared that it was "time to close the book on infectious diseases", HIV began to 'cruise' the San Francisco bath houses while severe acute respiratory syndrome (SARS) lay further in the future. In 1984 Margaret Heckler, then US Secretary for Health and Human Services, declared on behalf of the National Institutes of Health that "we hope to have a [AIDS] vaccine ready for testing in about 2 years."

How foolhardy it was to accept an invitation from Nature Medicine to comment on the next 20 years of HIV science! If we could foresee the future of research, then we would surely be doing it now. The other contributors to this issue have made the sensible prognostications, whereas anything I put forward here must be regarded as unsure prediction, idle speculation or even wild conjecture ${ }^{1}$.

The pace of HIV science, like all science, is driven by technology with unexpected breakthroughs. Without PCR, we would not have accurate measurements of HIV viral load and turnover; without rapid DNA sequencing and bioinformatics, we would not have such an exquisite database on HIV genetic variation; and if plant
\end{abstract}

Department of Immunology \& Molecular Pathology, University College London,

46 Cleveland Street, London, W1T 4JF UK.

e-mail: r.weiss@ucl.ac.uk virologists had not been curious to investigate gene silencing, we would not have RNA-mediated interference (RNAi) as a medical research tool. Thus, my message for future progress on HIV is that we ignore non-HIV research at our peril. No doubt this prophesy will fall on deaf ears at the funding agencies, especially those in the charitable sector: the late Bernie Fields' exhortation ${ }^{2}$ to "get back to basics" in HIV science is not part of their mission.

\section{Early successes of HIV science}

Our colleagues at the Institut Pasteur must have felt as frustrated as Cassandra when so few heeded their first report ${ }^{3}$ in May 1983 on a previously unknown retrovirus that was possibly associated with AIDS. At that time, 'lymphadenopathy virus' (LAV) was just one more candidate agent alongside other animal and human viruses, and alongside an idea that a fungal infection secretes a cyclosporin-like immunosuppressant. But none of us present at the Cold Spring Harbor Laboratory meeting on human retroviruses in the fall of 1983 should have failed to be impressed by how the French scientists hardened their evidence. By early 1984, they had detected the virus in individuals with AIDS, including gay men, two brothers with hemophilia ${ }^{4}$ and a heterosexual couple ${ }^{5}$ from Africa and their child, and had pointed out the similarity of LAV to animal lentiviruses on account of its cytopathic effects and morphology ${ }^{6}$. They were accurate in almost every finding, including the only correct interpretation of the open reading frames when the viral genome was cloned and sequenced $^{7}$. Hard on the heels of the second French report ${ }^{4}$ came news of other HIV isolates from the United States ${ }^{8,9}$.
Apart from the overoptimistic claims of a vaccine, early HIV research was extraordinarily fruitful (see accompanying reviews in this issue $\mathrm{e}^{10-12}$ ). Propagating HIV in T-cell lines provided ample antigen for diagnostic tests of infection that by 1985 had been translated into kits suitable for the mass screening of blood donors. CD4 was identified as the cellular binding receptor for HIV in 1984. The importance of the regulatory and auxiliary genes began to be elucidated in 1985. Azidothymidine (Zidovudine) became the first antiretroviral drug to enter clinical trials in 1986. Meanwhile, we began to grasp the scale of the AIDS pandemic unfolding before our eyes: 'slim' disease in Africa was indeed AIDS ${ }^{13}$.

\section{Controlling HIV transmission}

Figure 1 illustrates both the success of HIV science and the formidable challenges before us; it contrasts the control of mortality from AIDS in the United States with its exponential rise in sub-Saharan Africa. But Fig. 1a belies the heterogeneity of the African epidemic. As the 'four-city' studies have shown ${ }^{14}$, we still do not know why HIV spread explosively in some places and not in others. Fifteen years ago, AIDS in South Africa was seen in a handful of gay white men who had traveled to the United States, but now more than four million South African black men, women and children are infected with HIV. By contrast, it was estimated 15 years ago that about 7\% of adults in Kinshasa were infected, but this proportion remained stable until recently, despite the imploding infrastructure and human conflict that the Democratic Republic of Congo has suffered. Predicting the future of the HIV epidemic will be no easier than interpreting the recent past. 


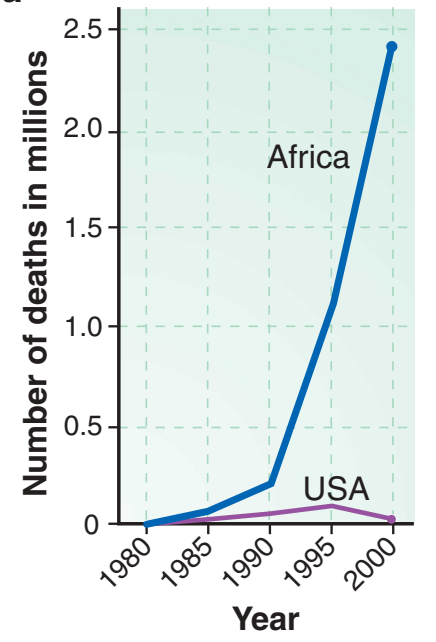

b

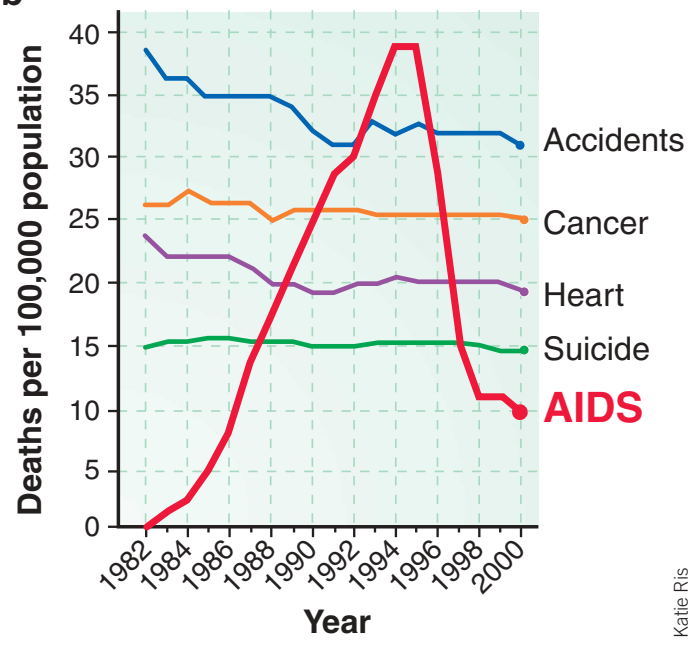

Figure 1 The human toll of AIDS. (a) Comparison of annual deaths from AIDS between subSaharan Africa (population 640 million) and the United States (population 273 million). (b) The five leading causes of death in men and women aged 25-44 years in the United States. Over the course of 10 years, AIDS came to be the chief cause of death in this generally healthy age group. The precipitous fall in mortality followed the introduction of highly active antiretroviral therapy (HAART), although the prevalence of HIV infection has not decreased. Reproduced with permission from ref. 58 from data provided by the Joint United Nations Programme on HIV/AIDS and the US Centers for Disease Control and Prevention.

Epidemiological evidence for the transmission of HIV by sexual and parenteral routes was clear before HIV was identified, and mother-to-child transmission soon after. The modes of transmission remain the same today and seem unlikely to change tomorrow. I previously questioned ${ }^{1}$ whether biting insects with large mouthparts might act as 'dirty needles' to transfer HIV passively, given that another lentivirus - equine infectious anemia virus - is transmitted in this way. But there is no evidence of transmission by insects, and if it were occurring then we would expect to see more children seroconverting before puberty.

It was recently postulated ${ }^{15}$ that in Africa, contaminated syringes and needles are responsible for more HIV transmission than is sexual contact. Although the number of infections by unsterile injections may have been underestimated during the pandemic phase of HIV, as well as during the mid-twentieth century ${ }^{16}$, sexual spread is driving the African pandemic ${ }^{17,18}$. If injection were the main route of HIV infection in Africa, as it has been in eastern Europe and China, then again we would expect to see more children of HIV-negative parents developing AIDS.

As Valdiserri et al. ${ }^{19}$ argue in this issue, much has been accomplished in reducing the transmission of HIV and, given politi- cal will, persuasive 'risk' education and sufficient resources, "the science exists to turn the pandemic around." Certainly, the continuing spread of disease could be slowed significantly, as has been seen in Senegal, Thailand and Uganda, but whether without an efficacious vaccine we can reduce $R_{0}$ to less than one-that is, reduce the mean rate of transmission from one infected person to less than one other person-remains speculative. India is currently estimated to have 4 million people infected with HIV (second only to South Africa), and this number could rise to 24 million in the next 10 years.

Perhaps we should not be too pessimistic. People do change their outlook and lifestyle in the face of devastating disease. For example, male circumcision has been identified as a factor that lessens the risk of female-to-male HIV infection in Africa $^{20}$. Who would have thought a few years ago that men imbued with their traditional social customs would readily come forward to take part in randomized controlled trials of adult circumcision? ${ }^{21}$

\section{Cell-to-cell transmission and tropism}

Whereas the 'sexual synapse' is a frequent route of HIV transmission from one person to another-one that may be blocked specifically by a condom and hopefully one day by vaginal viricides — the immunologi- cal synapse' is a pathway for virus transmission from cell to cell (see accompanying review in this issue $)^{22}$ and has been elegantly shown ${ }^{23}$ for human T-cell lymphotropic virus type I. We are only just beginning to understand the impact of the multiple delivery of virions from dendritic or other antigen-presenting cells to $\mathrm{CD} 4^{+}$ T-helper-cells.

I propose that the immunological synapse may account for the recent observation that although only a small proportion of $\mathrm{CD}^{+} \mathrm{T}$-cells in a lymphoid organ are infected by HIV, these cells contain several proviruses ${ }^{24}$. This type of 'multihit' infection at the cellular level may overcome the saturatable restriction factors of the host cell ${ }^{25,26}$. Packaged RNA genomes transcribed from more than one provirus in the same infected cell will assemble into heterozygous virions, which in turn will accelerate genetic recombination ${ }^{24}$ and the evolution of drug resistance and immune escape.

In the future, we should pay more attention to the comparative pathology of lentiviruses, including HIV-2 (ref. 27). In this issue, Stevenson ${ }^{11}$ points to the lessons to be learned from primates that are naturally infected with a high viral load but do not develop disease. He contrasts oncoviruses to HIV and the primate lentiviruses that can infect nondividing macrophages and dendritic cells. I argue further that all lentiviruses are macrophage-tropic, but only some infect lymphocytes (primate and feline immunodeficiency viruses). For example, let us consider Maedi-Visna virus, which is solely macrophage-tropic. Maedi-Visna in sheep is the prototypic disease from which lentiviruses derive their name ${ }^{28}$. Infected sheep develop a wasting disease and neurodegeneration similar to that seen in humans with AIDS, but they do not show T-helper-cell immune deficiency. As Maedi-Visna is remorselessly progressive, with a high rate of mortality, I have argued previously $^{29}$ that the infection, activation and apoptosis of T-cells in HIV are epiphenomena alongside the underlying progression of macrophage disease. Like the prophecies of Cassandra, this view remains unheeded perhaps because it would necessitate a complete reappraisal of both HIV pathogenesis and the inability of the immune system to ultimately control lentivirus infection.

Variation in HIV: evolution or noise?

Such a question has been posed for the 
variation observed in RNA viruses in gen$\mathrm{eral}^{30}$; for HIV, the answer is probably a lot of each. HIV generates variants at a far greater rate than do other RNA viruses such as measles, polio and even influenza ${ }^{31}$ (Fig. 2). The rapid radiation of HIV-1 group $M$ into the subtypes or clades that comprise today's pandemic strains and all of their variants could have arisen from a conjunction of two features of HIV: the extraordinarily high level of sustained replication and turnover in vivo ${ }^{11,32}$ and the functional tolerance of amino acid substitutions.

It is estimated that humans were first infected with HIV-1 group $\mathrm{M}$ about 70 years ago $^{33}$ and with HIV-2 about 60 years ago $^{34}$, with the viruses crossing from chimpanzees and sooty mangabeys, respectively ${ }^{35}$. In the early years, HIV-1 radiated out into the different clades that we know today, probably from small founder populations of virus. The regions in which HIV-1 has been present the longest have the most complex array of genotypes (Fig. 2). In the next 20 years the pattern will change, and an increasing number of circulating recombinant forms (CRFs) of HIV-1 will become apparent. Thus, the neat geographic delineation of subtypes - B in the Americas, E in Thailand, A and D in East Africa and C in southern Africa-are likely to be superseded by CRF viruses. Indeed, CRFs between HIV-1 groups $\mathrm{M}$ and $\mathrm{O}$ have been described $^{36}$, even though the parental genomes derive from distinct zoonotic events $^{35}$. It is possible that natural recombinants could arise between HIV-1 and HIV-2 now that HIV-1 has spread across West Africa, where HIV-2 was already endemic. Although there are some constraints to the co-packaging of HIV-1 and HIV-2 RNA ${ }^{37}$, it is worth investigating the possibility of hybrids in dually infected persons.

Does HIV variation matter? Although there is no evidence that HIV has evolved in terms of virulence or modes of transmission in the past 20 years, evolution of drug resistance $^{12}$ and of immune escape (see accompanying review in this issue ${ }^{38}$ and refs. 39,40) clearly occurs under selective pressure. Thus, HIV mutation and recombination have a great impact on therapy and vaccine design. I remain to be convinced, however, that the emphasis of vaccine design on the basis of clades is HIV science. Efficacious, broadly based vaccines require immunogens representing those regions of the virus that change the least. When these have been identified, clades can be addressed. For humoral immunity, the challenge is not only the immunogen itself but also the access of antibodies to the neutralization targets. Given the effect of the $N$-linked sugars of gp120 on immune escape from $\mathrm{HIV}^{39}$, the glycobiology of HIV is back in fashion.

Will the drop in AIDS mortality owing to antiretroviral therapy (Fig. 1) be maintained so that people on treatment can expect a normal life span? This will depend on the ability of the virus to develop multidrug resistance while remaining fit for transmission. We shall need new drug targets $^{12}$, but a big practical challenge in the future will be to marry good drug therapy to easy adherence, particularly in resourcepoor settings. This means that drug formulation must be designed to optimize appropriate use. Even then, if drugs administered to one infected individual are shared among their family or community such that several persons are simultaneously taking suboptimal doses, this could be a recipe for the rapid evolution and spread of multidrug-resistant HIV strains.

In the future, I expect that host genetic variation will also have a larger role in HIV science. In addition to identifying individual host factors ${ }^{26,41-43}$, whole-genome scanning for pharmacogenomics and for what I call 'infectogenomics' (host genes that affect the virulence of infection) will provide information on how to better manage HIV infection.

Global influenza 1996

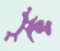

HIV single individual 6 years after infection

*
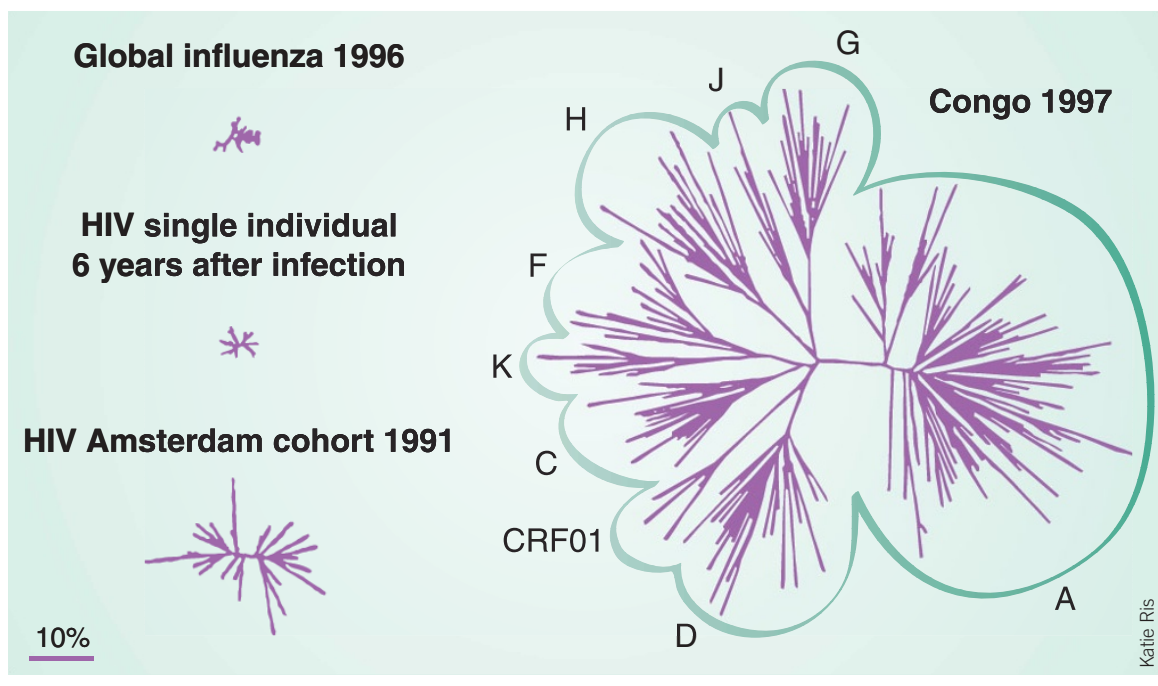

Figure 2 The scale of HIV variation. Sequence divergence of envelope glycoproteins of HIV (gp120, V2-C5) compared with that of influenza A H3 (HA1). The length of the spokes indicates the degree of divergence with the scale indicated. HIV variation in a single person 6 years after infection ( 9 genomes analyzed) is similar to that of worldwide influenza A (96 genomes analyzed) in a single year. The greatest degree of variation is in the Democratic Republic of Congo, where HIV first developed and has diversified into subtypes A-K (except for subtype B, prevalent in the West, and subtype $\mathrm{E}$, prevalent in Thailand). Adapted with permission from ref. 31.
Impact of HIV on immunization programs

HIV may have a severe impact on several of the immunization programs for children and adults. Inactivated or subunit vaccines may simply be ineffective in people infected with HIV: this has been shown for the pneumococcal polysaccharide vaccine $^{44}$, although antiretroviral therapy may restore responsiveness ${ }^{45}$. With viruses, HIV-positive individuals have the potential to become long-term shedders of what would otherwise be acute, short-lived infections, changing the dynamics of immunization and eradication. Thus, the large numbers of children with AIDS in Africa may impede campaigns to eradicate measles and polio and to protect against yellow fever. A recent detailed review ${ }^{46}$ on the safety, immunogenicity and effectiveness of vaccines in children with HIV concludes that the benefits currently far eneigh the risks. Nevertheless, epidemiological modeling will be needed to see whether one can minimize the untoward effects of HIV on other infectious diseases.

Another concern is that an 'attenuated' vaccine may itself act as a virulent pathogen in the immunocompromized individual. Case reports of severe complications of bacillus Calmette-Guérin (BCG), measles and polio have been reported, and World Health Organization (WHO) guidelines recommend withholding BCG and yellow fever vaccines from symptomatic children infected with HIV ${ }^{46}$. 
There is much concern over the risk of reintroducing smallpox vaccination to people infected with $\mathrm{HIV}^{47}$ because disseminated vaccinosis may ensue, as has been reported in an HIV-positive military recruit ${ }^{48}$.

\section{Interaction of HIV with other infections}

AIDS is characterized by opportunistic infections and by what we may call opportunistic neoplasms ${ }^{49}$. Some opportunistic infections in turn exacerbate HIV in a vicious cycle. Thus, genital herpes simplex infection is a risk factor for HIV transmission $^{50}$, while HIV increases and prolongs herpes shedding ${ }^{51}$. Other concurrent infections may ameliorate the risk or severity of HIV infection, as has been reported for GB virus $C^{52,53}$, scrub-typhus ${ }^{54}$ and dengue ${ }^{55}$. Elucidating the mechanisms of cross-protection may give us clues to controlling HIV.

Many opportunistic infections are either zoonoses or come from nonparasitic, freeliving microbes. Although they are typically not transmitted between humans, this pattern might change in the future if the opportunistic infections were to hop from one immunocompromised host to another. High-density immunodeficient populations are arguably unique in the annals of host-parasite evolution ${ }^{1}$.

Thus, viruses, bacteria, fungi and protozoa now have 42 million HIV-infected people in whom to adapt to human parasitism. Zoonoses occur naturally, but the prevalence of HIV infection could greatly increase the chances of an infection of animal origin, such as SARS, influenza, Ebola or Nipah viruses, to adapt more rapidly to human transmission. Individuals with AIDS would be the 'superspreaders', as they are for tuberculosis. It is perhaps reassuring that such a horrific situation has not yet occurred, but predictive modeling is required to determine whether it could occur in the future. The AIDS pandemic compounds the threat from the deliberate or accidental release of new infectious agents.

\section{Conclusion}

Like Cassandra, I shall end with a true prophesy that is at the same time optimistic and grim: 20 years from now, the risk of further lentivirus transfer from apes to humans ${ }^{35}$ will approach zero because feral chimpanzees will be extinct, thanks to the bushmeat trade and the Ebola epidemic $^{56}$, unless the apes are protected by immunization. Who would have predicted
20 years ago that we would have a vaccine for Ebola before one for HIV ${ }^{57}$ ?

\section{ACKNOWLEDGMENTS}

I thank A. Fassati, B. Korber, Á. McKnight, G. Towers and H. Weiss for critical comments. My research on HIV is supported by the Medical Research Council.

1. Weiss, R.A. Gulliver's travels in HIVland. Nature 410, 963-967 (2001).

2. Fields, B.N. AIDS: time to turn to basic science. Nature 369, 95-96 (1994).

3. Barré-Sinoussi, F. et al. Isolation of a T-lymphotropic retrovirus from a patient at risk for acquired immune deficiency syndrome (AIDS). Science 220, 868-871 (1983).

4. Vilmer, E. et al. Isolation of new lymphotropic retrovirus from two siblings with haemophilia $B$, one with AIDS. Lancet 1, 753-757 (1984).

5. Ellrodt, A. et al. Isolation of human T-lymphotropic retrovirus (LAV) from Zairian married couple, one with AIDS, one with prodromes. Lancet 1 1383-1385 (1984).

6. Montagnier, L. et al. A new type of retrovirus isolated from patients presenting with lymphadenopathy and acquired immune deficiency syndrome: structural and antigenic relatedness with equine infectious anaemia virus. Ann. Virol. 135E, 119-134 (1984).

7. Wain Hobson, S., Sonigo, P., Danos, O., Cole, S. \& Alizon, M. Nucleotide sequence of the AIDS virus, LAV. Cell 40, 9-17 (1985).

8. Gallo, R.C. et al. Frequent detection and isolation of cytopathic retroviruses (HTLV-III) from patients with AIDS and at risk for AIDS. Science 224 500-503 (1984).

9. Levy, J.A. et al. Isolation of Iymphocytopathic retroviruses from San Francisco patients with AIDS. Science 225, 840-842 (1984).

10. Fauci, S.A. HIV and AIDS: 20 years of science. Nat. Med. 9, 839-843 (2003)

11. Stevenson, M. HIV-1 pathogenesis. Nat. Med. 9, 853-860 (2003)

12. Pomerantz, R.J. \& Horn, D.L. 20 years of therapy for HIV-1 infection. Nat. Med. 9, 867-873 (2003)

13. Serwadda, D. et al. Slim disease: a new disease in Uganda and its association with HTLV-III infection. Lancet 2, 849-852 (1985).

14. Buvé, A. et al. Multicentre study on factors determining differences in rate of spread of HIV in subSaharan Africa: methods and prevalence of HIV infection. AIDS 15 (suppl. 4), S5-S14 (2001).

15. Gisselquist, D., Potterat, J.J., Brody, S. \& Vachon, F. Let it be sexual: how health care transmission of AIDS in Africa was ignored. Int. J. STD AIDS 14 148-161 (2003).

16. Drucker, E., Alcabes, P.G. \& Marx, P.A. The injection century: massive unsterile injections and the emergence of human pathogens. Lancet 358 , 1989-1992 (2001)

17. Joint United Nations Programme on HIV/AIDS (UNAIDS). Expert group stresses that unsafe sex is primary mode of HIV transmission in Africa (UNAIDS, Geneva, 2003)

18. Walker, P.R., Worobey, M., Rambaut, A., Holmes, E.C. \& Pybus, O.G. Epidemiology: sexual transmission of HIV in Africa. Nature 422, 679 (2003).

19. Valdiserri, R.O., Ogden, L.L. \& McCray, E. Accomplishments in HIV prevention science: implications for stemming the epidemic. Nat. Med. 9, 881-886 (2003)

20. Weiss, H.A., Quigley, M.A. \& Hayes, R.J. Male circumcision and risk of HIV infection in subSaharan Africa: a systematic review and meta-analysis. AIDS 14, 2361-2370 (2000).

21. Joint United Nations Programme on HIV/AIDS (UNAIDS). Male circumcision: current epidemiological and field evidence (UNAIDS, Geneva, 2003)

22. Pope, M. \& Haase, A.T. HIV-1 transmission, acute infection, and the quest for strategies to prevent infection. Nat. Med. 9, 847-852 (2003)
23. Igakura, T. et al. Spread of HTLV-I between lymphocytes by virus-induced polarization of the cytoskeleton. Science 299, 1713-1716 (2003).

24. Jung, A. et al. Multiply infected spleen cells in HIV patients. Nature 418, 144 (2002).

25. Cowan, S. et al. Cellular inhibitors with Fv1-like activity restrict human and simian immunodeficiency virus tropism. Proc. Natl. Acad. Sci. USA 99, 11914-11919 (2002).

26. Hatziioannou, T., Cowan, S., Goff, S.P., Bieniasz, P.D. \& Towers, G.J. Restriction of multiple divergent retroviruses by Lv1 and Ref1. EMBO J. 22, 385-394 (2003).

27. Reeves, J.D. \& Doms, R.W. Human immunodeficiency virus type 2. J. Gen. Virol. 83, 1253-1265 (2002).

28. Sigurdsson, B., Thormar, H. \& Palsson, P.A. Cultivation of visna virus in tissue culture. Arch. Virusforschung 10, 430-443 (1960).

29. Weiss, R.A. Lentivirus tropism and pathogenesis. Immunol. Lett. 66, 3-5 (1999).

30. Sala, M. \& Wain-Hobson, S. Are RNA viruses adapting or merely changing? J. Mol. Evol. 51, 12-20 (2000)

31. Korber, B. et al. Evolutionary and immunological implications of contemporary HIV-1 variation. Brit. Med. Bull. 58, 19-42 (2001).

32. Perelson, A.S. Modelling viral and immune system dynamics. Nat. Rev. Immunol. 2, 28-36 (2002).

33. Korber, B. et al. Timing the ancestor of the HIV-1 pandemic strains. Science 288, 1789-1796 (2000)

34. Lemey, P. et al. Tracing the origin and history of the HIV-2 epidemic. Proc. Natl. Acad. Sci. USA 100, 6588-6592 (2003).

35. Hahn, B.H., Shaw, G.M., De Cock, K.M. \& Sharp, P.M. AIDS as a zoonosis: scientific and public health implications. Science 287, 607-614 (2000).

36. Takehisa, J. et al. Human immunodeficiency virus type 1 intergroup $(\mathrm{M} / \mathrm{O})$ recombination in Cameroon. J. Virol. 73, 6810-6820 (1999).

37. Kaye, J.F. \& Lever, A.M. Nonreciprocal packaging of human immunodeficiency virus type 1 and type 2 RNA: a possible role for the p2 domain of Gag in RNA encapsidation. J. Virol. 72, 5877-5885 (1998)

38. McMichael, A.J. \& Hanke, T. HIV vaccines 1983-2003. Nat. Med. 9, 874-880 (2003)

39. Wei, X. et al. Antibody neutralization and escape by HIV-1. Nature 422, 307-312 (2003).

40. Richman, D.D., Wrin, T., Little, S.J. \& Petropoulos, C.J. Rapid evolution of the neutralizing antibody response to HIV type 1 infection. Proc. Natl. Acad. Sci. USA 100, 4144-4149 (2003).

41. Sheehy, A.M., Gaddis, N.C., Choi, J.D. \& Malim, M.H. Isolation of a human gene that inhibits HIV-1 infection and is suppressed by the viral Vif protein. Nature 418, 646-650 (2002).

42. O'Brien, S.J. \& Moore, J.P. The effect of genetic variation in chemokines and their receptors on HIV transmission and progression to AIDS. Immunol. Rev. 177, 99-111 (2000).

43. Gonzalez, E. et al. Global survey of genetic variation in CCR5, RANTES, and MIP- $1 \alpha$ : impact on the epidemiology of the HIV-1 pandemic. Proc. Natl. Acad. Sci. USA 98, 5199-5204 (2001).

44. French, N. et al. 23-valent pneumococcal polysaccharide vaccine in HIV-1-infected Ugandan adults: double-blind, randomised and placebo controlled trial. Lancet 355, 2106-2111 (2000).

45. Subramaniam, K.S., Segal, R., Lyles, R.H., Rodriguez-Barradas, M.C. \& Pirofski, L.A. Qualitative change in antibody responses of human immunodeficiency virus-infected individuals to pneumococcal capsular polysaccharide vaccination associated with highly active antiretroviral therapy. J. Infect. Dis. 187, 758-768 (2003).

46. Moss, J.W., Clements, C.J. \& Halsey, N.A. Immunization of children at risk of infection with human immunodeficiency virus. Bull. World Health Organ. 81, 61-70 (2003). 
47. Bartlett, J.G. Smallpox vaccination and patients with human immunodeficiency virus infection or acquired immunodeficiency syndrome Clin. Infect. Dis. 36, 468-471 (2003).

48. Redfield, R.R. et al. Disseminated vaccinia in a military recruit with human immunodeficiency virus (HIV) disease. N. Engl. J. Med. 316 , 673-676 (1987).

49. Boshoff, C. \& Weiss, R.A. AIDS-related malignancies. Nat Rev Cancer 2, 373-382 (2002).

50. Wald, A. \& Link, K. Risk of human immunodeficiency virus infection in herpes simplex virus type 2-seropositive persons: a meta-analysis. J. Infect.
Dis. 185, 45-52 (2002).

51. Mbopi-Keou, F.X. et al. Interactions between herpes simplex virus type 2 and human immunodeficiency virus type 1 infection in African women opportunities for intervention. J. Infect. Dis. 182 1090-1096 (2000).

52. Tillmann, H.L. et al. Infection with $G B$ virus $C$ and reduced mortality among HIV-infected patients. N. Engl. J. Med. 345, 715-724 (2001).

53. Xiang, J. et al. Effect of coinfection with GB virus $C$ on survival among patients with HIV infection. N. Engl. J. Med. 345, 707-714 (2001).

54. Watt, G. et al. HIV-1 suppression during acute scrub-typhus infection. Lancet 356, 475-479 (2000)

55. Watt, G., Kantipong, P. \& Jongsakul, K. Decrease in human immunodeficiency virus type 1 load during acute dengue fever. Clin. Infect. Dis. 36, 1067-1069 (2003).

56. Walsh, P.D. et al. Catastrophic ape decline in western equatorial Africa. Nature 422, 611-614 (2003).

57. Nabel, G.J. Vaccine for AIDS and Ebola virus infection. Virus Res. 93, 213-217 (2003).

58. Weiss, R.A. HIV and AIDS in relation to other pandemics. EMBO Rep. 4, 510-514 (2003). 